\title{
La filosofía del dar divino ad intra $y$ ad extra según Ignacio Falgueras
}

\section{The philosophy of divine giving ad intra and ad extra according to Ignacio Falgueras}

\author{
ADAM SOŁOMIEWICZ \\ Universidad de Navarra
}

Recibido: 23/04/2020 Aceptado:12/05/2020

\section{RESUMEN}

Según Ignacio Falgueras «ser» trascendentalmente significa «dar». Sólo en la perspectiva del Dar divino se puede comprender el dar trascendental humano, ya que éste proviene y depende radicalmente de aquél. El Dar divino y el dar humano son radicalmente distintos. Las notas primordiales del Dar divino ad intra (el dar interior en Dios) son: la comunicación interpersonal, la gratuidad y la sobreabundancia. Es un dar con ganancias, sin reservas y sin pérdidas. El Dar divino ad extra (la creación) tiene triple modalidad: el dar equívoco, el dar análogo y el dar unívoco. El dar trascendental humano refleja en cierta manera estas características del Dar divino.

\section{PALABRAS CLAVE \\ SER, DAR TRASCENDENTAL, LEONARDO POLO}

\begin{abstract}
According to Ignacio Falgueras «being» transcendentally means «giving». Only in the perspective of the divine Giving can one understand the human transcendental giving, because it comes from and depends radically on that. Divine and human giving are radically distinguished. The primordial notes of divine Giving ad intra (interior giving in God) are: interpersonal communication, gratuitousness and superabundance. It is a giving with gain, without reserve and without loss. The divine Giving ad extra (creation) has a triple modality:
\end{abstract}

(C) Contrastes. Revista Internacional de Filosofía, vol. XXVI No 1 (2021), pp. 123-137. ISSN: 1136-4076

Departamento de Filosofía, Universidad de Málaga, Facultad de Filosofía y Letras

Campus de Teatinos, E-29071 Málaga (España) 
equivocal giving, analogous giving and univocal giving. Human transcendental giving reflects in some way these characteristics of divine Giving.

KEYWORDS

BEING, TRANSCENDENTAL GIVING, LEONARDO POLO

\section{Planteamiento}

En una antropología basada en la noción de la sustancia, donde la persona humana se entiende como la unidad sustancial, al ser humano inevitablemente se adscribe los mismos rasgos radicales que pertenecen a la noción de la sustancia: la unidad intrínseca, la estabilidad, la separabilidad de otros entes. Lo que subsiste como sustancia es ante todo - en cierta maneraautosuficiente, independiente. Si tal autonomía o separabilidad ontológica comporta el rasgo fundamental de la persona, el punto de partida para las sucesivas consideraciones antropológicas (las cuestiones como la donalidad, el conocimiento, la relación con el otro, la libertad...) aparecen como accidentales, dado que lo fundamental para la sustancia es subsistir 'por sí' o 'en sí'. La sustancia primariamente no da de sí, sino que es en virtud de su unidad intrínseca ${ }^{1}$.

Leonardo Polo - sin rechazar la noción de la sustancia, sino recuperándola y reforzando su estatuto ontológico en el plano de la realidad material cósmicaconsideró el 'freno sustancialista' como el más serio obstáculo que bloqueó el desarrollo de la antropología filosófica hacia la antropología trascendental durante siglos ${ }^{2}$. Este trabajo no se dedica a exponer la propuesta antropológica de Leonardo Polo (la ampliación trascendental de los trascendentales metafísicos en la antropología), sino a presentar la 'filosofía del dar' del profesor Ignacio Falgueras, uno de los más eminentes discípulos de Polo ${ }^{3}$. La

1 «QQué significa sustancia? Realidad separada. ¿Y dónde está la suficiencia de la sustancia? En su separación. Pero el hombre no es sustancia, ni el ser del hombre es el ser de la sustancia, porque así como en la tradición de la teoría sustancialista se puede decir que la sustancia es tal porque está separada, lo característico del ser personal no es que esté separado, sino que es un quien y el quien es más que separado, es irreductible». Polo L., 2017, p. 141.

2 Este problema Polo lo detectó también en el seno del tomismo: «se trata de que el impulso que alimenta la filosofía tomista no llega al tema; quiero decir que se queda corto, o mejor, que está frenado por la herencia [sustancialista] aristotélica y el influjo de Averroes». Polo, L., 2016a, p. 24.

3 Leonardo Polo valoró como «excelente [la] investigación del dar» de Ignacio Falgueras (Polo, L., 2016a, p. 247, nota 1). Ángel Luis González afirmó: «Falgueras, [es] a mi juicio el autor que ha emprendido con más radicalidad y rigor el estudio de la estructura de lo que es y significa 
'filosofía del dar' es un modo de destacar con profundidad y rigor filosófico que la dimensión trascendental del ser humano equivale a dar, más que al mero subsistir separado de otros entes, característico de las sustancias.

El profesor Falgueras señala que su propuesta filosófica sobre el dar se inspira en sus «dos grandes maestros: S. Agustín y Leonardo Polo. De éste último - dice- tomo la inspiración del modo de filosofar, cuya clave última es la congruencia; del primero tomo la inspiración de una temática cristiana: todo cuanto somos y tenemos son dones de Dios» ${ }^{4}$. Y en cuanto que la índole donal humana depende radicalmente del Dar divino, lo primero que se expondrá aquí será el 'dar puro' intratrinitario de Dios y después su 'vertiente' ad extra (la creación). Estudiada la índole del Dar divino, desde tal perspectiva se tendrá el acceso al dar trascendental humano: cuestión que se investigará en un artículo aparte.

«'Nadie da lo que no tiene' reza el viejo adagio, pero - comenta Polo- eso es muy poco; nadie da si no es un dar, si no es intimidad» ${ }^{5}$. Si en la realidad causal -por ejemplo en la distribución de unos bienes materiales- no cabe dar sin un tener previo, en la actividad trascendental personal $-\mathrm{y}$, primariamente, en la Personal divina- el dar es del orden del ser: «el dar ha de ser, ante todo, la actividad más pura, alta y digna de todas» ${ }^{6} \mathrm{y}$, como en Dios, «el dar será también lo más alto en las criaturas» ${ }^{7}$. «De ese modo se está estableciendo que el dar comporta en el plano trascendental -como advierte Ángel Luis González- un horizonte insospechado» ${ }^{8}$ : una «filosofía del dar», según la designa Falgueras 9 .

Leonardo Polo suele describir la índole trascendental de la persona como efusiva, inagotable, que arde sin consumarse, puro sobrar, ademaseidad,

dar». «Falgueras ha tratado, [...] de modo riguroso y excelente, la índole de lo trascendental que estriba precisamente en el dar, en la actividad donal». González, Á. L., 2013, pp. 51, 54.

Como fuentes bibliográficas primarias para este artículo sirvieron estos tres artículos de Falgueras: «Aclaraciones sobre y desde el dar», 2008, pp. 51-82; «Dar equívoco, análogo y unívoco. El acto creador», 2011, pp. 2-17; «El dar, actividad plena de la libertad trascendental», 2013, pp. 69-108.

4 Falgueras, I., 2008, p. 51.

5 Polo, L., 2017, p. 147.

6 Falgueras, I., 2013, p. 104. Por eso «el adagio escolástico nemo dat quod non habet es un principio causal, no donal». Ídem, 1997, p. 65.

7 Ídem, 2008, p. 53.

8 González, Á. L., 2013, p. 54.

9 «Por este descubrimiento de que "ser es dar" empezó toda mi filosofía del dar». Falgueras, I., 2011, p. 4, nota 6. Falgueras subraya que su propuesta estriba en una «filosofía del dar» y no en una «filosofía del don» ya planteada en distintas corrientes del pensamiento contemporáneo (Cfr. Ídem, 2013, pp. 73-82). Así explica la ventaja de su enfoque novedoso: «La consideración centralizada en el don, aparte de desatender lo más peculiar de su índole pura, fragmenta la 
entonces el carácter donal resulta simplemente un término equivalente más. Falgueras, en cambio, insiste precisamente en el dar, subrayando que en la actuosidad espiritual «todo es dar y sólo dar», por lo cual se trata del «dar puro» ${ }^{10}$. La ventaja de la noción de dar sobre la efusividad, puro sobrar y otros sinónimos de la inagotabilidad trascendental libre, reside en su intrínseco carácter personal, ya que «sólo las personas pueden dar: [...] es algo bastante obvio que la actividad de dar (regalar, obsequiar) es una actividad interpersonal $\gg{ }^{11}$. Por otro lado, la estructura del dar indica su tríada interior: dar-aceptar-don ${ }^{12}$.

La realidad Una y Trina de Dios alcanzada como el dar no se ve «de modo intuitivo ni natural, sino que, gracias a la iluminación de la razón por la fe, cabe entenderlo de modo congruente» ${ }^{13}$. Dicho de otra manera, la comprensión filosófica del Dar divino y, por consiguiente, del dar trascendental humano, no resulta asequible al margen de la luz de la Teología de la $\mathrm{Fe}^{14}$. Y si aún hubiera sido asequible, la comprensión del dar -tan honda y rigurosa-, la cual se describe en esta investigación, surgió en el marco profundamente cristiano $^{15}$, donde la filosofía, siendo ancilla theologiae, estudia con su metodología propia temas alimentados por la luz de la Revelación cristiana ${ }^{16}$. En este sitio se puede subrayar, que aunque el tema de este trabajo es Dios (el Dar divino), no se trata aquí de un estudio teológico: mientras el método con el cual se procede es el de la «filosofía del dar», el tema también es filosófico,

actividad de dar, mientras que la consideración integral del dar incluye al don como uno de sus momentos. Por tanto, una filosofía del dar no sólo será más completa, sino más ajustada a su tema». Ibid., pp. 82-83.

10 Falgueras, I., 2008, p. 66.

11 Ibid., p. 54.

12 Quizá desde esta perspectiva es la noción de efusividad -por ser más general- la que tiene alguna ventaja sobre el dar, ya que el dar es efusivo y el aceptar también es efusivo. Falgueras habla, en cambio, del «dar donante» y del «dar aceptante» dando la impresión -pero sólo impresión- de cierta tautología. Si toda la actividad trascendental es dar, pero el dar y el aceptar se distinguen realmente, se trata de dos sentidos distintos del dar, aunque ambos trascendentales: 1. el dar como la efusividad o la actuosidad personal; 2. el dar como 'la fuente', 'el origen' o 'el miembro iniciador' del don.

13 Ibid., p. 68.

14 «Tomar como punto de partida la revelación cristiana tiene pleno sentido, puesto que la relevancia de la donación ha sido destacada precisamente por el cristianismo». Ídem, 2013, p. 82.

15 Como se ha señalado, las fuentes más directas de la «filosofía del dar» son San Agustín y Leonardo Polo.

16 Con esto, la filosofía del «dar puro, aunque permite acceder a cierto conocimiento congruente de la divinidad trina y una, no "disuelve" el misterio». Ídem, 2008, p. 77. 
propio de una disciplina filosófica llamada «teología natural» que investiga racionalmente las propiedades divinas.

\section{EL DAR DIVINO AD INTRA}

$\mathrm{Si}$ «dar es la actividad propia de Dios, entonces [...] no puede haber una actividad más alta que ésa ni en los cielos ni en la tierra. [...] Considerado el dar en su grado más alto, puede ser descrito nuclearmente como aquella actividad gratuita, libre y personal que nada presupone y nada excluye, pues nada pierde ni hace perder en su ejercicio, sino que innova lo que da. En este sentido puede ser calificado de actividad perfecta o pura: un don es perfecto cuando al darlo, por lo menos, ni pierde el que da, ni pierde el que lo acepta ni mengua el don» ${ }^{17}$.

De acuerdo con esta descripción del «dar puro» destacan tres notas primordiales del Dar divino ${ }^{18}$ : la comunicación interpersonal, la gratuidad y la sobreabundancia.

$1^{\circ}$ ) «La comunicación interpersonal ${ }^{19}$. Si un dar personal sólo lo es respecto de otra persona, la actividad donal divina es «comunicativa» y lo es del Don personal: «cada persona [en Dios] "es" dando comunicativamente a otra persona $»^{20}$. Y en ese «dar puro» «todo es dar, si él nada deja por dar» ${ }^{21}$, «en él, cada persona da, y se da, íntegramente, sin reservarse nada» ${ }^{22}$. Luego, «cuanto más intenso es el dar menos pérdida lleva consigo, hasta el punto de que las donaciones personales más profundas [...] no llevan consigo pérdida alguna, ni por parte del que da ni por parte del que recibe ni por parte de lo dado» ${ }^{23}$. En definitiva, el dar divino considerado como «la comunicación interpersonal» es un dar personal «sin reservas» $\mathrm{y}$ «sin pérdidas».

$\left.2^{\circ}\right)$ La gratuidad. Al «dar puro» no le puede faltar la iniciativa libre y gratuita, con lo cual está exento de toda necesidad. Tampoco da de lo que tiene, porque si una Persona divina tuviera con anterioridad más que otra, la identidad originaria de las tres se quebraría: «el Padre no da de lo que tiene

17 Ibid., pp. 53, 54-55.

18 Cfr. Ídem, 2013, pp. 87-92.

19 «Es lo que en la teología cristiana se suele exponer mediante las expresiones "ad aliud" (San Agustín) o "relación subsistente" (Santo Tomás)». Ibíd., p. 88. «Nec tamen omne quod dicitur In Deo secundum substantiam dicitur. Dicitur enim ad aliquid, sicut Pater ad Filium, et Filius ad Patrem». San Agustín de Hipona, De Trinitate, XV, c. 3. n. 5, 1059. «Persona igitur divina significat relationem ut subsistentem». Santo Tomás de Aquino, Summa Theologiae, I, q. 29 , a. 4 , c.

20 Falgueras, I., 2013, p. 87.

21 Ídem, 2008, p. 66.

22 Ibid., 2013, p. 89.

23 Ídem, 2008, p. 54. 
al Hijo, porque para eso debería distinguirse en Él el ser, el tener y el dar [...]. El que da de lo que tiene no se da Él, sino algo suyo, lo cual significa que se reserva a sí mismo del dar. In divinis no se da de lo que se tiene, pero tampoco lo que se tiene (como si fuera algo distinto del dar), sino que se da el dar, es decir, la actividad de dar genera y espira personas que se dan íntegramente» ${ }^{24}$. En pocas palabras, el «dar puro» gratuito es «dar sin reservas» $»^{25}$.

3) La sobreabundancia. «No se da de lo que se tiene previamente, sino que se innova al dar» ${ }^{26}$. Pero, ¿cómo un dar 'sin reservas' puede ser un dar que no pierde? Más bien, al darlo todo debería perderlo todo. No obstante Dios, «si al dar no pierde, puede darlo todo sin perder nada. El 'sin pérdidas' y el 'sin reservas' son no sólo compatibles, sino connaturales al dar supremo puro $»^{27}$. Tal dar es una «realidad sobrante, aportadora, innovante, sin que reporte necesariamente pérdidas o menguas para nada ni para nadie» ${ }^{28}$ : «no puede perder nada, porque lo que se dan las personas divinas es el dar, y se lo dan enteramente» ${ }^{29}$. Las tres Personas divinas que se comunican en una donación mutua irrestricta no forman, sin embargo, un todo de tres partes o momentos, sino una «plenitud pletórica y eterna» ${ }^{30}$ :

la Trinidad no es un conjunto de tres, sino la identidad de tres. Si fuera un conjunto, habría de totalizarse, pero la totalización implica una reserva, un 'nada más que'. [...] El 'sin reservas' evita toda parcialización, y, con ello, que ninguna Persona sea entendida como superior, anterior o posterior a otra, así como también evita que las tres sean partes de un todo resultante ulterior. En consecuencia, no existe actividad alguna superior, ni anterior ni ulterior al dar sin reservas, el cual es eternidad activa ${ }^{31}$.

24 Ibid., 2013, pp. 89-90.

25 Por eso se puede afirmar, con las palabras de Alberto Vargas, que Dios «es pura vida donal que se regala, que da Su ser, que se da a Sí mismo». Vargas, A., 2019, p. 163.

26 Falgueras, I., 2008, p. 55.

27 Ibid., p. 63.

28 Ibíd., p. 55.

29 Ídem, 2013, p. 91.

30 Ibid., p. 91. Falgueras señala que «el dar sin pérdidas ni reservas es una actividad tan plena y desbordante que se puede denominar pletórico [en vez de "totalizante"]. Es ésta una forma de hablar con la que intento sugerir la insuperable grandeza de lo divino sin caer en las limitaciones propias del hombre. La noción de plenitud "pletórica" es congruente con la simplicidad como actividad, que expresada, en cambio, con otros términos lleva a frecuentes confusiones». «Con la noción de plenitud pletórica [...], he intentado -continua Falgueras- hacer inteligible cómo la trascendentalidad o naturaleza divina lo es todo sin totalizarse, es perfecta sin haber comenzado ni acabado, está en todo sin confundirse con nada, se comunica a todo sin que se le añada ni le falte nada». Ídem, 2008, pp. 77, 80.

31 Ibíd., p. 65. 
En definitiva, 'dar puro' sobreabundante es el dar 'innovante', «el exceso sin medida del dar sin pérdidas ni reservas» ${ }^{32}$.

Ahora bien, tal Dar divino comunicativo, gratuito y sobreabundante es uno o simple, pero no unitario sino trinitario. En tanto que no se trata de un 'todo' de tres dares, contradictorio a la Identidad Originaria o a la simplicidad de Dios, «el dar se nos muestra como una actividad no monolítica, sino integrada por actos distintos, los cuales guardan un orden entre sí: al donante le corresponde la iniciativa en el dar, al aceptador le corresponde la acogida del dar, y al don el exceso o sobra que colma la mutua donación de los anteriores ${ }^{33}$. De esta manera, si cada Persona divina se identifica con el Dar divino, pero se distingue según la estructura tríadica de ese dar, se pude hablar del «dar donante, el dar aceptante y el dar-don [los cuales] consuman un solo dar» ${ }^{34}$. De acuerdo con la Teología de la Fe, resultará «acertado entender el amor divino según la distinción entre dar, aceptar y don, que se asimilarían, respectivamente, al Padre, al Hijo, y al Espíritu Santo» ${ }^{35}$. De este modo el donante será Dios-Padre, el aceptante Dios-Hijo y el don Dios-Espíritu Santo, «y sin embargo no son tres dioses, sino un solo Dios» ${ }^{36}$.

La Identidad de las tres Personas divinas comporta el misterio más grande de la fe y aunque es imposible desvelarlo, cabe, por lo menos, asomarse a él y entender algo de su verdad. En tanto que la Trinidad no es un todo de tres partes, pero sí, la Identidad de los tres «ingredientes» ${ }^{37}$ del dar, su distinción indica un orden interior de las Personas divinas: «el orden trascendental originario está integrado por un triple acto cada uno de índole donal, a la par que esa índole donal los identifica $»^{38}$. Dicho de otra manera, «el dar puro es compatible con el orden. [...] Los tres activos personales del dar, aunque integran un dar idéntico, incluyen referencias de orden: la iniciativa del donante es lo primero, la aceptación de esa iniciativa, es lo segundo, y el don como comunión de

32 Ibid., p. 65, nota 50. Polo afirma, tal vez parafraseando a Falgueras, que «donar es dar sin perder, la actividad superior al equilibrio de pérdidas y ganancias». PoLo, L., 2015b, p. 229.

33 Falgueras, I., 2008, pp. 58-59.

34 Ídem, 2013, p. 91.

35 Polo, L., 2015a, p. 314, nota 31. «Regalar es propio de Dios. La estructura triádica del amor personal, que se manifiesta en el regalo, es una sugerencia muy clara de la Trinidad Divina. Cabe decir que los miembros de esta estructura son el dar, el aceptar y el don, los cuales se pueden apropiar a cada una de las tres personas divinas: el dar caracterizaría al Padre, la aceptación sería propia del Hijo y el don, del Espíritu Santo». Ibíd, p. 322.

36 Confesión pseudo-atanasiana "Quicumque», n. 16 (Denzinger, 2000, 75).

37 Por no encontrar otro término mejor, Falgueras habla de los «ingredientes» del dar puro: «Los ingredientes del dar no son partes suyas». «El dar implica una pluralidad trina de ingredientes reales (donante, aceptador, don), a la vez que la unidad de ellos o su simplicidad activa (un solo dar)». Falgueras, I., 2008, pp. 67, 81.

38 Ibíd., p. 69. 
iniciativa y aceptación, es lo tercero. Pero 'primero', 'segundo' y 'tercero' no son ni indicaciones de tiempo ni de jerarquía, sino puras indicaciones de origen o procedencia: el dar puro se integra desde la iniciativa, por la aceptación y en el don $»^{39}$. En definitiva, como señala Polo, «la Trinidad y la unidad es 'Dreieinigkeit' como dicen los alemanes: 'trino-unidad'. No es que, por una parte, sea uno y, por otra, sea trino, sino que por ser trino es uno. [...] No se puede poner la esencia o el ser de Dios antes de las personas divinas, pues en ese caso el Padre no sería 'origo totius divinitatis'»" ${ }^{40}$.

¿Cómo la relación de origen o procedencia en Dios puede no implicar la distinción de anterioridad o de jerarquía? No la implica en cuanto que es 'dar puro' 'sin reservas' (cada persona se da enteramente en su Identidad y no deja nada sin dar) y 'sin pérdidas' (en la plena comunicación interpersonal divina «ninguno de los actos que integran el dar se extingue [...] en el otro, sino que los tres están co-dando en el dar idéntico» ${ }^{41}$ ). En definitiva, según Falgueras, el Dar divino es uno en tanto que da 'sin reservas', y trino, en tanto que da 'sin pérdidas' ${ }^{42}$.

Por último, tras caracterizar el Dar Íntimo divino -o el Dar divino ad intra-, como comunicativo, gratuito y sobreabundante, Uno (idéntico) y Trino según la estructura tríadica del dar, cabe afirmar que «existen tres actividades que al ser comunicadas o dadas no se pierden: el ser, el entender y el amar: [...] ser, entender y amar como actividades puras tienen como índole [...] la trascendentalidad activa o el dar» ${ }^{43}$. En este sentido «el ser $d a$ sin reservas, el entender da el dar (o acepta) sin reservas, el amar se da sin reservas, de manera que los tres son un idéntico dar» ${ }^{44}$.

Según lo indicado, el Dar divino no sólo es, sino que es cognoscitivo y amoroso, con lo cual se puede afirmar que el ser, el conocer y el amar son los tres sentidos trascendentales idénticos del «dar puro». ¿Cada uno de ellos corresponde propiamente a una Persona divina? Si fuera así, el Padre daría el ser al Hijo y al Espíritu Santo, el Hijo daría el conocer el Padre y al Espíritu

39 Ibid., pp. 81-82.

40 Polo, L., 2015a, p. 263.

41 Falgueras, I., 2008, p. 68. Por eso el engendrar o el «proceder es intrínseco a la actividad pura de dar, por lo que no implica ni adelanto ni retraso ni pérdida o extinción alguna, ni por parte de los dares ni tampoco por parte del dar. Por consiguiente en la Trinidad Santa ni la unidad es anterior a las personas, ni las personas a la unidad, sino de una sola vez (simplokós) e incompuestamente unidad idéntica de tres». Ibíd.

42 «La iniciativa, la aceptación y el don supremos pueden ser distintos, porque su dar es "sin pérdidas": la iniciativa no se pierde en la aceptación ni ambas en el don; pero lo que los hace un solo dar es que cada uno da "sin reservas"». Ibid., p. 67.

43 Ibid., pp. 55, 60.

44 Ibíd., p. 68. 
Santo, y el Espíritu daría el amor al Padre y al Hijo, lo que presupondría carencias previas de estos trascendentales correspondientes en otras Personas, lo que es, claramente, inadmisible. El ser, el conocer y el amar son, por tanto, los 'trascendentales idénticos' de la Unidad Divina, con lo cual, también de cada una de las tres Personas. Por eso, en cierto sentido se puede decir, que «cada una de las tres divinas personas es trina, [...] pero no son nueve actos, sino tres que dan íntegramente, y, al revés, el dar íntegro es un solo dar, no tres dares inidénticos» ${ }^{45}$. «En conclusión, ser es dar, entender es dar, amar es dar» ${ }^{46}$.

Recapitulando lo dicho sobre el Dar divino ad intra cabe decir que se trata de la actividad transcendente a todo lo creado, la más actuosa, 'pletórica' y eterna, que es Una, en virtud de la Identidad divina, y Trina, en virtud de las tres Personas divinas que se comunican según la estructura tríadica del dar -el dar donante (el Dios-Padre), el dar aceptante (el Dios-Hijo) y el dardon (el Dios Espíritu Santo)-, en la cual cada Persona da 'sin reservas' y 'sin pérdidas'.

\section{EL DAR DIVINO AD EXTRA}

El Dar divino es 'pletórico', eterno y sobreabundante, por lo cual no le falta nada y nada se le puede añadir. Esto no quiere decir que Dios es inmutable sin más, como si fuera un ser inerte, ya que la comunicación donal intratrinitaria es lo más activo que existe, desbordante, y si no crece, es más que crecer o es híper-crecimiento ${ }^{47}$ : «que Dios sea el crecimiento originario absoluto - comenta Vargas- no significa que Dios crezca, sino que Dios es el Origen del crecer, que es puro crecer» ${ }^{48}$. En este contexto el dar ad extra, o sea, la creación, comporta un «gran nudo misterioso [...]: ¿cómo puede terminar ad extra una actividad que es intrínsecamente ad intra? [...] ¿Qué sentido tiene, pues, un ad extra de la actividad plena y pletórica?» ${ }^{49}$.

Ante estas preguntas el entendimiento humano -ni siquiera en su cima de la fe intelectual- no es capaz de dar ninguna respuesta concluyente. Lo que se puede afirmar es que la donación ad extra no puede ser necesaria (Dios es libre de cualquier necesidad), con lo cual el acto creador es de índole libre,

45 Ibid., p. 69.

46 Ibid., p. 81.

47 Polo, tratando del crecimiento personal humano, se pregunta por el crecimiento de Dios: «¿Qué pasa con la Trinidad? No crece, porque la Trinidad es originaria y Ser Originario es más que crecer». Polo, L., 2017, p. 154.

48 Vargas, A., 2019, p. 166.

49 Falgueras, I., 2011, p. 9. 
cognoscitivo y amoroso.

Para entender el carácter del 'dar puro' ad extra y distinguirlo del Dar divino ad intra, sirve partir de esta afirmación de Falgueras: «lo ad extra del dar puro estriba en que el acto creador va dirigido a aquello que de suyo no $\mathrm{da}, \mathrm{y}$, por tanto, en la medida en que ser es dar, va dirigido a lo que no es (ni da)», con lo cual «ni tan siquiera va dirigido a un receptor impersonal que sea previo o simultáneo: es un dar que da sin receptor alguno previo» ${ }^{50}$. En pocas palabras: a diferencia del dar ad intra, que va dirigido a un 'co-donante' -es decir, a otra Persona divina-, el dar ad extra de entrada se dirige a la nada. Si el primero es enteramente recíproco, el segundo es unilateral: crear el ser ex nihilo depende exclusivamente del Creador ${ }^{51}$. Por eso, mientras «el ex nihilo parece afectar a la criatura [...], el ad extra afecta a la actividad de Dios. Se trata de un solo misterio, el de la creación, pero visto desde sus dos vertientes» ${ }^{52}$.

Según lo dicho se comprende que Dios no equivale a un antecedente de la creación, de manera que «la criatura no era una posibilidad en Dios antes de ser creada, sino pura nada. Por consiguiente, ser libre para Dios no significa la posibilidad de crear o no crear, ser libre para Dios significa 'dar' sin precedentes ni pérdidas» ${ }^{53}$. Asimismo «Dios no crea algo que le sobre, ni la creación es un sobrar de Dios que requiera ser recogido ${ }^{54}$, con lo cual no cabe otra justificación del dar ad extra que ésta: «la creación hunde sus raíces en el misterio del amor divino» ${ }^{55}$.

Ahora bien, ¿cuál de los 'ingredientes' del Dar divino da el ser en la creación? ¿Es el Dios-Padre «todopoderoso, creador del cielo y de la tierra, de todo lo visible y lo invisible» ${ }^{56}$ ? ¿O el Dios-Hijo, «por quien todo fue hecho» ${ }^{57}$ ? ¿O el Dios-Espíritu Santo «Creador» ${ }^{58}$ ? Si cada una de las actividades intratrinitarias (Dar-Aceptar-Don) se dirige 'sin reservas' a otra, o sea, es una Unidad de tres actividades divinas 'co-donantes', no tiene sentido atribuir a una de Ellas la obra ad extra, porque ninguna 'se desvía' hacia fuera,

50 Ibid., p. 4.

51 Polo señala que «Dios "se ocupa" de la nada exclusivamente en atención a la criatura; es decir, la crea excluyendo la nada de ella y, por tanto, distinguiéndola de la nada». PoLO, L., 2016a, p. 156.

52 Falgueras, I., 2011, p. 9.

53 Ídem, 2008, p. 58.

54 Ídem, 2011, p. 9.

55 Polo, L., 2016a, p. 156.

56 Concilio I de Constantinopla, El credo constantinopolitano, (Denzinger, 2000, 150).

57 Ibíd.

58 Es llamado así en el antiquísimo himno «Veni Creator Spiritu». Cfr. Catechismus Catholicae Ecclesiae, 1997, n. 291. 
hacia la nada. En rigor, el Dar divino ad intra «es la actividad de dar pura sin término externo alguno» ${ }^{59}$. Por eso, la creación sólo se puede explicar como «un acto libre iniciado por las tres divinas personas en común» ${ }^{60}$.

Esto quiere decir, que «la criatura no es algo que se den las personas divinas entre sí, sino un término exterior para el dar, un término que no da el dar a Dios ni se da. Ahí estriba la exterioridad (ad extra): en que la criatura no co-da originariamente al creador, sólo es término de su dar» ${ }^{61}$. En definitiva, el dar ad extra es «un dar cuya iniciativa radica en la Trinidad entera, pero carece de receptor previo y termina en un don. [...] El dar pleno y pletórico opera plena y pletóricamente, pero -al crear- opera un dar que tiene términos externos» ${ }^{62}$.

Así pues, si el dar ad intra no tiene término exterior, el dar ad extra da lugar a una diversidad de términos externos (según su índole peculiar) y una «pluralidad innumerable de criaturas como términos suyos» ${ }^{63}$. Falgueras distingue tres modos diversos «en que el dar divino suscita de la nada a cada tipo de términos creados» ${ }^{64}$, y llama esos dares «equívoco, análogo [y] unívoco» ${ }^{65}$.

$\left.1^{\circ}\right)$ El término del 'dar equívoco' es el acto de ser del universo físico. En cuanto que es un dar que «no va dirigido a ser aceptado» esta creación impersonal «no da, sino sólo recibe (sin receptor previo)» ${ }^{66}$, por lo cual no es don en sentido estricto. Con esto, «equívoco» no quiere decir «equivocado», ya que Dios no se equivoca creando, sino «que otorga un don que no da propiamente» ${ }^{67}$, pero «da» «en un sentido equívoco al divino y al personal» ${ }^{68}$ : redundando en dones. «El redundar del ser del mundo creado es su esencia, un despliegue de bienes, o dones potenciales, que sólo otras criaturas (espirituales) pueden convertir en dones personales» ${ }^{69}$. En definitiva, «el ser del mundo es la más baja de las criaturas hechas por el dar divino, un don que

59 Falgueras, I., 2011, p. 3.

60 Ibid., p. 10.

61 Ibid., p. 11.

62 Ibid.

63 Ibid., p. 3.

64 Ibíd.

65 Ibid., p. 11.

66 Ibid., p. 5.

67 Ibid., 5, nota 12.

68 Ibid., p. 5.

69 Ibíd. 
no da, pero redunda en dones, y, así, es reflejo de la abundancia y sobra de la plenitud pletórica del dar divino» ${ }^{70}$.

$2^{\circ}$ ) El segundo modo de dar ad extra es el «dar análogo» que equivale a la creación de la persona humana. Ese dar ya no es «equívoco», puesto que la persona es un don en el sentido estricto en tanto que da la aceptación a Dios de ser creado, pero tampoco es un dar intratrinitario -que se da «sin reservas»-, sino «análogo» a éste. En el «dar análogo» se trata de crear dones que son dares. La persona humana, pues, es llamada a dar libremente, aunque sus dones no son dares (el hombre no crea personas a diferencia de Dios, capaz de dar dones personales).

En definitiva, «lo análogo ha de ser realmente distinto respecto de aquello de lo que es análogo, pero en algo semejante a él. Y así el dar de la criatura elevada [o sea, de la persona humana] es semejante al dar del Logos divino sólo en cuanto que, después de recibida la llamada o libertad (respecto de lo cual no es libre), sí es libre de aceptar (o no) lo que ha recibido, haciéndolo suyo (o no). La distinción radica en que la criatura elevada no puede tener iniciativa en el dar respecto de Dios» ${ }^{71}$. Dicha falta de iniciativa del hombre está clara en el sentido del dar como donatio essendi, pero negar la iniciativa del dar trascendental humano parece afectar la libertad personal ${ }^{72}$. Tal libertad ha de ser asegurada por el «dar unívoco».

$3^{\circ}$ ) El tercer «modo» del Dar divino ad extra es el «dar unívoco» que se corresponde con la Encarnación del Verbo Divino. «Lo que llamo -dice Falgueras- "dar unívoco" es la asumición [el acto de asumir] de la naturaleza humana por el Verbo, cuyo término es la humanidad de Cristo, la tercera

70 Ibid.

71 Ibid., p. 7.

$72 \mathrm{Si}$ es cierto que la persona humana no tiene la iniciativa del dar respecto de Dios en el primer «momento», cabe preguntar por si la tiene por ser persona. Si la persona humana es donal constitutivamente, la iniciativa del dar ha de ser humana; si no lo es, tal iniciativa tiene que apoyarse en una realidad superior, es decir, en Dios. La tesis de Falgueras: el «dar unívoco» es el que «comunica a la criatura la iniciativa del dar» (Ibíd., p. 16), parece jugar a favor de la segunda solución.

Sin embargo, la semejanza del dar humano con el divino no sólo está en la aceptación del Dar Creador, como sugiere Falgueras, sino también en la iniciativa libre del dar personal humano a Dios. Sin solucionar ahora este cuestión, se puede recordar las palabras de San Agustín que aporta una advertencia valiosa al respecto: el dar humano tiene siempre sentido de 'devolución'. Con todo, esa devolución humana es libre; por tanto, es un dar verdadero. «¿Pues de quién das? De él, [de Dios]. Si dieses de lo tuyo, sería prodigalidad; pero dando de lo que es de él, es devolución. ¿Qué tienes que no hayas recibido?». San Agustín de Hipona, Salmo 95, 15. Polo se pronuncia en el mismo sentido: «La iniciativa donante primordial arranca de Dios, y al hombre corresponde devolvérsela de acuerdo con su ser y con su esencia». Polo, L., 2016a, p. 251. En fin, el dar humano como devolución no carece de la iniciativa humana. 
criatura» ${ }^{73}$. Es unívoco, porque comporta «un dar unitivo, que tiene un término creado o ad extra, pero al que une consigo y hace capaz de dar en el mismo sentido en que [da] el Verbo» ${ }^{74}$. De esta manera queda salvada no sólo la distinción ser-nada ${ }^{75}$, sino, ante todo, la distinción superior: Creadorcreación, ya que, «al ser asumida, la naturaleza humana de Cristo se convierte en expresión directa del Verbo divino, o sea, en verbo del Verbo, y así queda incluida en el seno de la intimidad divina» ${ }^{76}$.

De tal modo «este dar unívoco es el dar ad extra supremo, que no puede ser superado por ningún otro, ya que no cabe otro dar divino que dé más que la inclusión de lo ad extra en lo ad intra, de la criatura en el creador, sin que ni la una se disuelva ni el otro mengüe. El término de tan inconcebible dar es, insisto - dice Falgueras-, la criatura suprema, primogénita de toda criatura, por razón de la cual todo fue creado: es la humanidad de Cristo» ${ }^{77}$.

Con estos dos breves párrafos queda esbozado el núcleo de la concepción del 'dar unívoco'. Más allá de lo dicho sólo se señalará, que la cuestión de la humanidad de Cristo como la 'criatura suprema' o como el mayor de los «tres tipos de criaturas ${ }^{78}$ merece una discusión a la luz de la siguiente afirmación de Leonardo Polo: «sugiero que la asunción [de la humanidad de Cristo] hace las veces de la creación, pues, en rigor, la humanidad de Cristo no es creada» ${ }^{79}$. Como se ve, Polo descarta decididamente la consideración de la Encarnación del Verbo en términos de creación. No obstante, esta divergencia con la posición de Falgueras posiblemente es de índole meramente 'terminológica', dado que los dos se refieren a la elevación sobrenatural de la naturaleza humana, lo que Polo denomina, por su parte, como la nueva creación ${ }^{80}$. Con todo, hablar de «tres tipos de criaturas» no parece lo más afortunado, ya que el acto de ser del universo y las co-existencias humanas son criaturas en el

73 Falgueras, I., 2011, p. 7.

74 Ibid.

75 Como en toda la creación ex nihilo.

76 Ibid., p. 8 .

77 Ibíd. En consecuencia, «el dar unívoco, que reúne sin confusión lo ad intra y lo ad extra del dar divino, contiene en sí el germen de la mediación entre las criaturas y Dios, así como la recapitulación final de todas las cosas». Ibíd.

78 Cfr. Ibid., p. 3.

79 Polo, L., 2016b, p. 591. «Conviene tener en cuenta que en la humanidad de Cristo lo natural está enteramente elevado al nivel sobrenatural. He aquí una razón más para sostener que dicha humanidad es asumida sin necesidad de creación». «Si la humanidad que Cristo asume fuera creada, se daría una composición entre Dios y la criatura, es decir, que algo ontológicamente propio de la Segunda Persona de la Trinidad sería creado. Pero nada es creado sin acto de ser. Ahora bien, el acto de ser de la humanidad de Cristo es la Persona del Verbo». Polo, L., 2015a, pp. 230, 236.

80 Polo, L., 2016b, p. 527. 
sentido estricto, mientras que la elevación sobrenatural es criatura sólo en el sentido analógico, pues significa, precisamente, la divinización de lo creado.

Resumiendo lo dicho sobre el Dar divino ad extra, cabe decir que se trata de una actividad creadora que tiene diversos términos fuera de Dios. Si el 'dar equívoco' no es dar en el sentido propio (su don no da), el 'dar análogo' lo es, pero no en todos los sentidos del dar (es un don que da propiamente, pero no 'sin reservas' ni 'sin pérdidas', ni sus dones son dares). El 'dar unívoco', en cambio, «consiste en que la iniciativa del dar pleno y pletórico divino otorga ad extra un don que da en todos los sentidos del dar, es decir, a imagen del dar divino». De esta manera «los términos resultantes de la iniciativa creadora divina poseen en propio el modo de dar que les ha sido otorgado» ${ }^{81}$.

\section{A MODO DE CONCLUSIÓN}

El dar trascendental humano es radicalmente distinto del Dar divino. A la vez, es en cierta manera semejante a éste. Falgueras señala que la distinción entre el Dar divino y el dar creado estriba: «(i) en que en las criaturas no todo es dar, pues antes (jerárquicamente) son dadas o dones que dares, (ii) en que los dones que ellas dan no dan, pues sus dones no son personas, y (iii) en que sus dares no son un solo dar, pues no son plenos» ${ }^{82}$. Comparando el dar humano con el Dar divino intratrinitario se ve, que el humano no es comunicación interpersonal (la persona humana no es capaz de dar personas y cabe preguntar si es capaz de dar-se plenamente), ni es del todo gratuito (parece que la persona humana no es capaz de dar sin reservas), ni es sobreabundante (cuando da, con ello sufre ciertas pérdidas). Sin embargo, el niño es un don mutuo del hombre y de la mujer en la unión matrimonial; la entrega de la propia vida por el otro muestra la plena gratuidad del amor humano sin reservas; cada acto del amor es desbordante: la persona humana cuando ama sale de sí misma, se trasciende.

Tras estudiar el dar puro divino intratrinitario y creador, habrá que investigar si el dar trascendental humano, no siendo intratrinitario ni creador, es un verdadero dar. Según Ignacio Falgueras, a pesar de que no toda la actividad humana es dar, el dar es la actividad personal por antonomasia.

\section{REFERENCIAS BIBLIOGRÁFICAS}

VV.AA., 1997: Catechismus Catholicae Ecclesiae. Cittá del Vaticano: Libreria Editrice Vaticana.

DENZINGER, H. - HÜNERMANN, P., 2000: Enchiridion Symbolorum definitionum et declarationum de rebús fidei et morum. Barcelona: Herder.

81 Falgueras, I., 2011, p. 16.

82 Ídem, 2013, p. 105. 
FALGUERAS, I., 1997: Crisis y renovación de la metafísica. Málaga: Universidad de Málaga.

—_ 2008: «Aclaraciones sobre y desde el dar». En FALGUERAS, I.; GARCÍA GONZÁlEZ, J. A. (eds.), Antropología y trascendencia. Málaga: Universidad de Málaga, pp. 51-82.

— 2011: «Dar equívoco, análogo y unívoco. El acto creador». En Miscelánea Poliana, 32, pp. 2-17.

— 2013 : «El dar, actividad plena de la libertad trascendental». En Studia Poliana, 15, pp. 69-108.

GONZÁLEZ, Á. L., 2013: Persona, libertad, don. Lección inaugural del curso académico 2013-2014. Pamplona: Universidad de Navarra.

POLO, L., 2015a: Epistemología, creación y divinidad, en Obras Completas, Vol. XXVII. Pamplona: EUNSA.

— 2015b, Filosofía y economía, en Obras Completas, Vol. XXV. Pamplona: EUNSA.

_ 2016a: Antropología trascendental. Tomo I: La persona humana, en Obras Completas, Vol. XV. Pamplona: EUNSA.

- 2016b: Antropología trascendental. Tomo II: La esencia de la persona humana, en Obras Completas, Vol. XV. Pamplona: EUNSA.

—, 2017: Persona y libertad, en Obras Completas, Vol. XIX. Pamplona: EUNSA.

SAN AGUSTÍN DE HIPONA, De Trinitate, PL 42.

, 1966: Salmo 95. Obras de San Agustín, tomo XXI, trad. Fuertes Lanero, M. Madrid: BAC.

SANTO TOMÁS DE AQUINO, Summa Theologiae. En http://www. corpusthomisticum.org/

VARGAS, A., 2019: «El crecimiento del ser personal». En Studia Poliana, 21, pp. 141-170.

Adam Solomiewicz es Doctor en Filosofía por la Universidad de Navarra

Lineas de Investigación:

Antropología trascendental de Leonardo Polo

Publicaciones recientes:

(2020): «Las cuatro descripciones de la libertad trascendental según Leonardo Polo», Estudios Filosóficos Polianos, 7, 25-41.

(2019-2020): «La dualidad radical de la persona humana. Un intento de proseguir la antropología trascendental de Leonardo Polo», Excerpta e dissertationibus in philosophia. Cuadernos doctorales de la facultad eclesiástica de filosofía, 29, 99-193.

Correo electrónico: adam.solomiewicz@gmail.com 
